\title{
Drug diversion of oxycontin in chronic pain syndrome
}

\author{
Sean O'Domhnaill, Declan O'Keeffe, Kevin Malone
}

Ir J Psych Med 2006; 23(3): ??-??

\begin{abstract}
A case is described in which a man with chronic pain syndrome (CPS) presented to a city General hospital in suicidal crisis after referral from a provincial psychiatric unit, having taken an overdose of a variety of medications, precipitated by the absence of his opioid (Oxycontin) analgesia which he had been abusing intra-nasally. This is to our knowledge the first reported case in Europe of drug diversion from oral to intranasal use of Oxycontin, a controlled-release preparation of the synthetic opiate, oxycodone hydrochloride. There is also a dearth of reference to the abuse potential of this agent in the European literature. As sufferers from chronic pain syndrome increase in number, and opiate prescription rates worldwide are maintained, this case highlights the potential of opiate abuse or dependence and drug diversion emerging as a significant medical problem in CPS patients in Europe.
\end{abstract}

Key words: Chronic pain; oxycodone; depression; suicide; substance abuse.

\section{Introduction}

Over the past three decades, there has been a significant increase in opiate abuse in Ireland. ${ }^{1}$ A newer oral opiate derivative analgesic, oxycodone, has been marketed in Ireland in recent years for chronic pain syndrome (CPS). We describe the first recorded case in the European literature of intranasal oxycodone abuse, prescribed orally for a patient with CPS.

\section{Case history}

Overview

A 39 year old Irish national was admitted to a Dublin city hospital Pain Management Programme (PMP) from a provincial psychiatric unit with symptoms of depression and suicidal ideation secondary to his CPS and his admitted dependence upon his prescribed oxycodone, which he was taking intra-

\footnotetext{
*Sean O’Domhnaill, MB, DPM, MRCPsych, Dip. Cog Therapy. Locum Consultant in General Psychiatry with Special Interest in Substance Misuse, St Loman's Hospital, Mullingar, Co Westmeath, Ireland. Declan O'Keefe, MB, BCh, BAO, FFA (RCSI) Consultant Pain Management Service Programme, Kevin Malone, MB, BCh, BAO, MRCPsych, Prof of Psychiatry, Department of Psychiatry and Mental Health Research, St Vincent's University Hospital, Dublin 4, Ireland.

${ }^{*}$ Correspondence

SUBMITTED: JANUARY 18, 2006. ACCEPTED: JUNE 8, 2006.
}

nasally. He was to be commenced on methadone, having taken two recent overdoses in "serious" attempts to kill himself.

Almost a year before, the PMP had prescribed Oxycontin, titrated to $60 \mathrm{mg}$ b.i.d for CPS. He informed the staff at presentation to the psychiatric unit that he was abusing his Oxycontin by crushing it into powder and snorting it intranasally. His one month supply was consequently lasting only two weeks. He ascribed his suicidality and hopelessness to his CPS, present since 1987 (see Table 1).

Since 1994 he has attended the PMP. In February 2002, Oxycontin 60mg b.i.d and Oxynorm (immediate-release formula) $10 \mathrm{mg}$ b.i.d prm were prescribed. The patient, having previously snorted both cocaine and heroin intra-nasally was aware of the abuse potential of the drug when converted to a powder form. Apparently he had discovered on the Internet that Oxycontin could be taken intra-nasally once the coating was disabled by crushing. He began to use the oxycodone accordingly.

Tolerance reduced his prescription to lasting two weeks, although withdrawal symptoms were minimal, possibly due to his other psychotropic medication.

\section{Past psychiatric history}

In 1994, the patient was referred to group therapy in a psychiatric hospital in Dublin after his mother died. The Coroner's inquest recorded a verdict of death by misadventure, from a combination of disulfiram and alcohol.

The group therapy "eased" a lot of his "residual anger" toward his mother for "drinking herself to death". He was granted permanent disability status after another accident in 1996. At that time, he commenced paroxetine from his GP and bromazepam $1.5 \mathrm{mg}$ t.i.d for agitation. He continued on this medication for eighteen months and denies misusing it. He drank heavily, falling asleep while socialising on occasion. In 2001 he was commenced on venlafaxine XL 75mg once daily by a private psychiatrist who then referred him back to his catchment area service, and the antidepressant dose was increased incrementally to $225 \mathrm{mg}$ once daily by 2002 . Alprazolam $0.5 \mathrm{mg}$ t.i.d was added for anxiety/agitation and olanzapine for insomnia.

\section{Psychiatric assessment at most recent hospital- isation}

Early childhood and education

The patient was the younger son of a sibship of two. He described a "very happy" childhood, but conceded that his mother was severely alcohol-dependent. He enjoyed school at primary level, and was popular and good at games.

When he moved to secondary school, he never really settled down, as he felt like "a loner". His academic perfor- 


\begin{tabular}{|c|c|c|c|c|}
\hline Age & Injury & Cause & Treatment & Sequelae- physical/psychological \\
\hline 18 & \# femur \& tibia & Playing football & POP \& NSAIDs. & Needed crutches for mobility. Cannabis use began. \\
\hline 19 & \# femur & $\begin{array}{l}\text { Friend fell on him } \\
\text { while both intoxicated }\end{array}$ & POP \& NSAIDs. & $\begin{array}{l}\text { Increased use of Cannabis. Commenced weekly MDMA, } \\
\text { cocaine \& heroin intranasally. }\end{array}$ \\
\hline 24 & facial pain & Idiopathic & Celecoxib and night-splint. & $\begin{array}{l}\text { Travelled to England to his father and attended a London } \\
\text { Hospital privately, monthly for three years. Good response }\end{array}$ \\
\hline 30 & Whiplash & RTA & $\begin{array}{l}\text { NSAIDs and physiotherapy } \\
\text { Facet joint syndrome required } \\
\text { cervical nerve-block. Risotomy. }\end{array}$ & $\begin{array}{l}\text { Chronic pain developed. Patient began abusing alcohol } \\
\text { and increased his illicit drug-use. Referred to group } \\
\text { therapy in Dublin for bereavement issues and } \\
\text { benefited from same. Referred to Pain Management } \\
\text { Service. }\end{array}$ \\
\hline 35 & Whiplash & RTA & $\begin{array}{l}\text { NSAIDs and Celecoxib. } \\
\text { Paroxetine and Bromazepam } \\
\text { prescribed. }\end{array}$ & $\begin{array}{l}\text { Pain worsened. Patient became depressed and } \\
\text { referred to psychiatry. }\end{array}$ \\
\hline
\end{tabular}

mance declined. At 16 years old he began experimenting with Cannabis. He "dabbled" in illicit drug use for several years.

\section{Adulthood}

At 18 years of age he suffered a fractured femur and tibia playing football, which left him incapacitated for most of his Leaving Certificate year. He barely passed his examination and decided to repeat same. The following year he again fractured his femur. Two weeks later he repeated his Leaving Certificate in hospital. He slept through most of the examinations due to the sedative analgesia and failed his examination.

\section{Employment history}

His leg healed. He worked in the construction industry, subsequently qualifying in Construction Studies. He moved to London to live with his father who was employed in the construction industry there. A year later he moved home again.

\section{Medication}

Upon admission under the care of the PMP, his medication was venlafaxine XL 225mg once daily, amitryptiline $50 \mathrm{mg}$ nocte, alprazolam $0.5 \mathrm{mg}$ t.i.d and olanzapine $10 \mathrm{mg}$ nocte. His oxycodone prescription had been discontinued in the psychiatric unit. The pain management team did not carry out urine toxicology, although the patient admitted intermittent cannabis use.

\section{Pre-morbid personality}

He described himself as "lively and outgoing" and felt that he was reasonably affable toward others. He admitted to being somewhat impulsive in nature, leading to a chequered employment record and being fired from his last job as a materials manager.

\section{Mental state examination}

Upon admission to the PMP service, mental state examination revealed a well-dressed and groomed man who engaged fully with the interviewer. He appeared relaxed throughout the interview, but expressed low mood, strong suicidal ideation and high degree of hopelessness in a detached and matter of fact manner. He felt his relationship of nine years, from which he had a five year old son, was "doomed", resulting from his disability and incapacity to contribute to the domestic income. He had become emotion- ally distant from his partner. There was no contact between them during his hospital stay. He was not psychotic or thought-disordered and was of high-average intelligence. He acknowledged the intra-nasal oxycodone abuse and agreed to a methadone substitution programme.

Physical examination was essentially normal. He described pain on all movements, none of which were restricted in range to any significant degree.

\section{Treatment}

Under the supervision of the psychiatric team his psychotropic medication was rationalised. The PMP titrated his methadone against his pain severity, using it additionally as a substitute for his oxycodone dependence.

Discharge plan

At his self-discharge after three weeks hospitalisation he was no longer expressing suicidal ideation. His prescription was; methadone $15 \mathrm{mg}$ t.i.d.; celecoxib $200 \mathrm{mg}$ b.i.d; zolpidem $10 \mathrm{mg}$ nocte and venlafaxine XL $225 \mathrm{mg}$ daily. He was referred back to the local psychiatric service for further substance rehabilitation and follow-up.

\section{Discussion}

To our knowledge, this is the first reported case in the European literature of drug diversion of Oxycontin from oral to intranasal route during the treatment of a chronic pain syndrome, a well recognised phenomenon in the US. ${ }^{9}$ However, it should be noted that oxycodone is administered as an intra-nasal spray in circumstances where the oral route is compromised or more rapid onset of analgesic action is required..$^{11}$ The use of crushed oxycontin has been reported to be associated with total necrosis of the nasal septum, sinuses and soft palate. It is likely that it will feature in the future as a street drug of abuse. ${ }^{12}$ Known in the US as 'Hillbilly Heroin' or 'poor man's heroin', its abuse potential was first realised in the Appalachian region and West Virginia in particular. ${ }^{9}$ The drug has a street value in the US ranging from 50 c to $\$ 1$ per milligram. The amount of crime related specifically to oxycodone is now a matter of statistic. In some counties of the Appalachian region, it accounts for up to $80 \%$ of indictable crime.

Some pharmacies in the US have refused to stock the drug for security reasons. Chronic pain is a recognised risk factor 
for both suicide ${ }^{2}$ and depression. ${ }^{3}$ The involvement of psychological therapists in the treatment of chronic pain is now considered essential ${ }^{5}$ as is the role of liaison psychiatry. ${ }^{6}$ Pain clinics commonly combine anaesthetists, psychiatrists and psychologists, a feature that is likely to grow with the extension of Consultation-Liaison psychiatry.

\section{Conclusion}

Oxycodone is an opiate with anxiolytic and euphoriant effects. It is widely prescribed in Ireland and the UK as a treatment for chronic pain, its only approved indication.

It has a greater oral bio-availability than morphine and is estimated to be approximately twice as potent. ${ }^{10}$

As the diagnosis of chronic pain syndrome increases in frequency, and opiate prescription rates worldwide are maintained, this case highlights the potential of opiate abuse/ dependence and drug diversion emerging as a significant medical problem in CPS patients in Europe, as in the US. Our case report illustrates oxycodone's abuse potential and we must expect to see more of the same in the future, and be suitably circumspect in our prescribing, particularly in those with a history of illicit drug use, harmful use of alcohol or prescription drug misuse. ${ }^{9}$

\section{Declaration of interest: None}

\section{References}

Moran R, O'Brien M, Dillon L, Farrell E. Overview of Drug Issues in Ireland 2000. Drug Misuse Research Division. Health Research Board. 2001.

Fishdain DA. The Association of Chronic Pain and Suicide. Semin Clin Neuropsychiatry 1999 Jul;4(3):221-7

Hendler N. Depression caused by chronic pain. J Clin Psychiatry. 1984; 45: 30-38. Fisher BJ, Haythornthwaite JA, Heinberg LJ, Clark M, Reed J..Suicidal Intent in Patients with Chronic Pain; Pain 2001 Jan; 89 (2-3):199-206

Hitchcock LS, Ferrell BR, McCaffery M.. The Experience of Chronic Non-Malignant Pain. J Pain Symptom Manage 1994 Jul; 9(5): 312-8.

Chronic Pain. David J. Rowbotham. Edited by M. Dunitz. 2000.

Reich J, Tupin JP, Abramowitz Sl.. Psychiatric diagnosis in chronic pain patients. Am J Psychiatry 140: 1495-1498, 1983.

Melzack R. Pain and the Neuromatrix in the Brain. Journal of Dental Education. 2001. Vol $65 ; 1378-1382$

Suleman R, Abourjaily H, Rosenberg M.. Oxycontin-Misuse and Abuse. J Mass Dental Society. 2002; 51: 56-58.

Physicians Desk Reference. 67th Edition. 2003.

Dale O, Hjortkjaer, Kharasch ED. Nasal administration of opioids for pain management in adults. Acta Anaesthesiol Scand. 2002 Aug;46(7):759-70. Review.

in adil. A. Tota inhalation of crushed OxyContin. Ear Nose Throat J. 2005 Aug;84(8):512, 514, 516. 